Article

\title{
Analysis of Factors Contributing to Changes in Energy Consumption in Tangshan City between 2007 and 2012
}

\author{
Jialing Zou ${ }^{1,2,3}$, Weidong Liu ${ }^{1}$ and Zhipeng Tang ${ }^{1, *}$ \\ 1 Key Laboratory of Regional Sustainable Development Modeling, Institute of Geographic Sciences and \\ Natural Resources Research, CAS, Beijing 100101, China; zoujl.12b@igsnrr.ac.cn (J.Z.); \\ liuwd@igsnrr.ac.cn (W.L.) \\ 2 University of Chinese Academy of Sciences, Beijing 100049, China \\ 3 School of Geography, Beijing Normal University, Beijing 100875, China \\ * Correspondence: tangzp@igsnrr.ac.cn; Tel.: +86-10-6488-9529 \\ Academic Editor: Tomonobu Senjyu \\ Received: 11 January 2017; Accepted: 16 March 2017; Published: 18 March 2017
}

\begin{abstract}
The aim of this paper is to identify the correlations between energy consumption and the factors that control usage in the city of Tangshan. To do this, we first analyze the current status of Tangshan's economic development and energy consumption, and then applied the logarithmic mean Divisia index to identify the factors affecting the changes in energy consumption of all sectors. The findings are summarized as follows: (1) secondary industry accounts for an extremely high percentage of industry in Tangshan city, much higher than the national average; from 2007 to 2012, the proportion of secondary industry increased in Tangshan city; (2) Tangshan's energy consumption in 2013 was nearly twice that in 2005. Coal and coke coal consumption was responsible for $96.2 \%$ of total energy consumption in 2005 and 95.1\% in 2013; (3) Tangshan's energy intensity decreased from 3.00 tce/10 thousand Yuan in 2005 to 1.85 tce/10 thousand Yuan in 2013. However, the energy intensity of Tangshan was far more than the average for China, and the decline in Tangshan's energy intensity was much slower than the average for China; (4) The technical effect plays a dominant role in decreasing energy consumption in most sectors, and the scale effect is the most important contributor to increasing energy consumption in all sectors. Input structural and final use structural effects play different roles in energy consumption in different sectors.
\end{abstract}

Keywords: Tangshan; energy consumption change; input-output model; logarithmic mean Divisia index

\section{Introduction}

Global warming negatively affects the sustainable development of both ecosystems and the global environment. As a result, conserving energy and reducing carbon emissions have become common global goals to combat climate change. The Chinese government has committed to reducing carbon emissions per unit gross domestic product (GDP) by $40 \%-45 \%$ by 2020 compared to the level in 2005 . In the 21st Conference of Parties to the United Nations Framework Convention on Climate Change, the Chinese government further committed to reduce carbon dioxide emissions per unit GDP by $60 \%-65 \%$ compared to the 2005 level, with the peak carbon dioxide emission being reached by 2030 . China distributed the emission reductions specifically to local governments during the 12th Five-Year Plans and will continue this policy during the 13th Five-Year Plans [1,2]. In this context, an in-depth study of the trends in urban energy consumption and influencing factors will help achieve the overall goals of saving energy and reducing emissions.

The city of Tangshan, locating in Hebei Province, is a resource-based city that is rich in coal mines and has a prosperous iron-steel industry. Because of the prevalence of heavy industry, Tangshan has a 
strong and invariant demand for energy, and carbon emissions are a prominent problem [3-5]. In this context, an in-depth study of trends in urban energy consumption and the factors that influence them contribute toward the overall goals of saving energy and reducing emissions. The main purpose of this paper is to identify the main factors contributing to the change in energy consumption in Tangshan. To realize this goal, a decomposition technique is employed to analyze the influential factors. Currently, structural decomposition analysis (SDA) and index decomposition analysis (IDA) are the most-used decomposition techniques for energy consumption and carbon emissions [6,7].

Of these techniques, the first (SDA) breaks down already decomposed variants on the basis of known economic relationships and mathematical rules, which broadens functionality and makes for a more thorough, convenient, and systematic analysis [7]. SDA is thus usually based on input-output tables and has been widely applied in studies that deal with energy and environmental issues [8]. In addition, Su and Ang [9] developed the multiplicative SDA method, proposing the further use of attribution analysis via the generalized Fisher index in the context of structural decomposition analysis, while in order to evaluate performance indicators for multi-regional comparisons, these workers also put forward a spatial-SDA framework for analysis [10].

Wachsmann, Weber, Kim, and Cellura and co-workers [11-14] used SDA to analyze the changes in energy consumption in Brazil, America, Korea, and Italy, respectively. They found that structural changes contribute the most to reductions in energy consumption. Since the reform and opening up in China, energy consumption has increased quickly and continues to rise; for example, energy consumption increased from 1549 Mtce in 2001 to 4260 Mtce in 2014 [15]. Scholars have paid much attention to the reasons for the growth in energy consumption in China. Xia, Li, Zhang, Zheng, and Zhao and co-workers [16-21] all applied SDA to analyze the main factors that have contributed to changes in Chinese energy consumption in different stages and showed that end-use increases have tended to cause this growth. In addition, other researchers have considered changes in energy consumption at the provincial level [22].

The alternative approach, IDA, mainly consists of Laspeyres index decomposition (LID) and Divisia index decomposition (DID). Compared with DID, the multiplier decomposition relation is difficult to separate in LID. Thus, DID is widely used in decomposition analysis. With the continuous development of DID, logarithmic mean Divisia index (LMDI) becomes more complete. In the calculation of decomposition, LMDI can completely decompose the remainder with non-explainable remainders. LMDI can be divided into LMDI-I [23] and LMDI-II [24]. LMDI-I and LMDI-II will not produce an explainable remainder. However, the estimates of the effects of energy consumption change given by the two methods tend to differ slightly. Earlier studies that compared the two methods from the viewpoint of index numbers found that both have their strengths and weaknesses. Both methods satisfy most of the tests of index numbers, which are considered to be relevant to IDA; while both satisfy most index number tests considered relevant to IDA, additive LMDI-I fails the proportionality test, while additive LMDI-II fails the aggregation test [25].

LMDI is widely used for the quantitative study of factors that contribute to changes in energy consumption and carbon emissions because its data requirements are not high, and there is no unexplained residual. From the viewpoint of spatial scale, LMDI can be used at the country level, for example, to study energy consumption and carbon emission in China, the European Union, and other areas [26-31]. Many studies have also been carried out on energy consumption and carbon emissions at the provincial level [32-37], while such studies are relatively rare at the city level [38]. Research has also been conducted at the sector level; for example, Choi and Oh studied the energy consumption and carbon emissions associated with the Korean manufacturing industry [39], and Zhang and co-workers investigated the energy consumption of transportation services in China [40]. In addition to the SDA and the LMDI, the DEA method is sometimes also applied to decompose factors associated with changes in energy efficiency $[5,41]$.

As described above, LMDI has many advantages. However, LMDI does not take intermediate input into consideration and thus ignores the changes in energy consumption attributed to energy 
consumption structure between sectors [42]. As a result, an increasing number of studies have used the SDA-LMDI model to analyze the forces driving changes in the economic system [43], energy consumption and energy intensity [11], and $\mathrm{CO}_{2}$ emissions [44]. Building on these earlier studies and considering energy consumption as a variable that can be decomposed, this paper applies a new method that incorporates the advantages of both the LMDI and input-output approaches, enabling complete decomposition and explaining how energy consumption structure affects changes in energy consumption. Further, because studies that deal with energy consumption changes at the level of cities are relatively rare, we chose the city of Tangshan as a case study in order to develop a better understanding of environmental problems in the Beijing-Tianjin-Hebei region as well as the characteristics of energy consumption in China. The remainder of this article is organized as follows. Section 2 describes the LMDI method and the data used. Section 3 presents the trends in industrial structure and energy consumption in Tangshan city. Section 4 presents the effects of different factors on the changes in energy consumption in Tangshan city based on LMDI. Section 5 presents the conclusions and offers some policy implications.

\section{Method and Data Preparation}

\subsection{Decomposition Method}

In order to decompose energy consumption by sector, it is necessary to comprehensively calculate this variable. However, complete analysis of the energy consumption encapsulated within an industrial supply chain requires an appropriate method that considers the energy use in intermediate production processes by other industrial sectors that comprise the supply chain [45]. One appropriate method to capture energy consumption flows in the economy is the environmental input-output model (EIO), which is extended from the standard Leontief input-output model [46,47]. This tool allows the calculation of direct energy consumption from a sector's final demand, as well as the indirect energy consumptions from other sectors within the same supply chain. The EIO model can be expressed as follows

$$
E=e(I-A)^{-1} Y=e \times C \times Y,
$$

In this expression, $E$ denotes the embodied energy that results from final demand, while $e$ is the row vector of direct energy consumption of unit total output, $I$ is the unit matrix, $A$ is the direct consumption coefficient matrix, $C$ is the Leontief inverse matrix, and $Y$ is the column vector of final demand. Thus, importing final demand structure into Equation (1) and adopting the competitive import hypothesis [48], Equation (2) can be generated, as follows:

$$
E=e(I-A)^{-1} Y=e \times C \times s \times y,
$$

In this expression, $s$ denotes the column vector of final demand structure, and $y$ is final demand. We used the input-output model for the city of Tangshan to construct a decomposition method to analyze the factors that influence the embodied energy within this region. According to Ang's research [25], the LMDI approach is preferable to other index composition methods. Ang [49] provided practical guide for the LMDI method, and Ang \& Liu [50] proposed a technique for handling the zero values in the LMDI approach. Therefore, we carried out the decomposition analysis by combining the input-output model and the LMDI approach.

In order to apply the LMDI approach, Equation (2) can be rewritten as:

$$
E=\sum_{j} \sum_{i}\left(e_{i}^{T} C_{i j}\right) s_{j} y
$$

Clearly, over the course of one time period, changes in embodied energy or final demand carbon will result from a range of effects. As a result, different techniques, compositions, and scale effects were first used to measure the effects of trade on the environment [51], as widely applied in the 
sectors of trade and environment [52]. Thus, building on previous research, we also define technique effect as the impact of sectoral changes on direct energy intensity, while holding all other variables constant. The structural effect includes not just input but also final use structural effects, again if all other variables are held constant. Input structure corresponds to production structure, while final use structure represents consumption structure, reflecting structural changes between supply and demand, respectively. Finally, scale effect measures changes in energy consumption generated by variation in the total amount of final use if all other variables are held constant. On this basis, it is possible to generate one general form for all four effects as well as formulas for their calculation.

Given that $\Delta$ denotes the changes in each variable, and superscript $T$ represents the transpose of a vector, changes in $E$ between the time points $t_{0}$ and $t_{1}$ can be decomposed using Equation (2) as follows:

$$
\Delta E=E^{t_{1}}-E^{t_{0}}=f\left(\Delta e^{T}\right)+f(\Delta C)+f(\Delta s)+f(\Delta y),
$$

According to Equation (4), and following Ang [48] and Ang \& Liu [49], the components of Equation (3) can be expressed as follows:

$$
\begin{gathered}
f\left(\Delta e^{T}\right)=\sum_{j} L_{j} \sum_{i}\left(w_{i j} / w_{j}\right) \cdot \ln \left(e_{j}^{t_{1}} / e_{j}^{t_{0}}\right), \\
f(\Delta C)=\sum_{j} L_{j} \sum_{i}\left(w_{i j} / w_{j}\right) \cdot \ln \left(C_{i j}^{t_{1}} / C_{i j}^{t_{0}}\right), \\
f(\Delta s)=\sum_{j} L_{j} \ln \left(s_{j}^{t_{1}} / s_{j}^{t_{0}}\right) \text { and } \\
f(\Delta y)=\sum_{j} L_{j} \ln \left(y_{j}^{t_{1}} / y_{j}^{t_{0}}\right),
\end{gathered}
$$

It therefore follows that:

$$
\begin{gathered}
L_{j}=\left(E_{j}^{t_{1}}-E_{j}^{t_{0}}\right) /\left(\ln E_{j}^{t_{1}}-\ln E_{j}^{t_{0}}\right), \\
w_{i j}=\left(g_{i j}^{t_{1}}-g_{i j}^{t_{0}}\right) /\left(\ln g_{i j}^{t_{1}}-\ln g_{i j}^{t_{0}}\right) \text { and } \\
w_{j}=\left(g_{j}^{t_{1}}-g_{j}^{t_{0}}\right) /\left(\ln g_{j}^{t_{1}}-\ln g_{j}^{t_{0}}\right),
\end{gathered}
$$

Similarly:

$$
\begin{gathered}
g_{i j}=e_{i} C_{i j} \text { and } \\
g_{j}=\sum_{i} g_{i j} .
\end{gathered}
$$

The terms $f\left(\Delta e^{T}\right), f(\Delta C), f(\Delta s)$ and $f(\Delta y)$ represent variation in technique, input structural, final use structural, and scale effects in the embodied energy of Tangshan final demand during the period from $t_{0}$ to $t_{1}$, respectively. Thus applying Equations (3)-(13), we calculated and analyzed variations in energy consumption in Tangshan resulting from these four factors.

\subsection{Data Preparation}

We used the 2007 and 2012 input-output table for Tangshan city from Hebei Provincial Bureau of Statistics [53,54]. We merged the original 42 sectors (Table A1) into 28 sectors (Table 1) and adjusted the price in 2012 to be comparable to that in 2007. We extracted energy data from the Tangshan Statistical Yearbook 2008-2013 [55-60], and calculated sector-unit energy consumption using standard coal values. Thus, values for total energy consumption are based on balance tables for the city of Tangshan as well as specific industrial sector energy measures resulting from industrial consumption, designated size, and total industrial consumption. 
Table 1. Sector number according to its denomination of national economy of Tangshan from 2007-2012.

\begin{tabular}{ccc}
\hline Sector Code & Sector Description & $\begin{array}{c}\text { Original Sectors of } \\
\text { Input-Output Table }\end{array}$ \\
\hline S1 & Agriculture & $\mathrm{s} 1$ \\
S2 & Mining of coal & $\mathrm{s} 2$ \\
S3 & Mining of oil and gas & $\mathrm{s} 3$ \\
S4 & Mining of metal & $\mathrm{s} 4$ \\
S5 & Mining of nonmetal & $\mathrm{s} 5$ \\
S6 & Tobacco, food and beverage & $\mathrm{s} 6$ \\
S7 & Textile & $\mathrm{s} 7$ \\
S8 & Wearing apparel, dressing and dyeing of fur & $\mathrm{s} 8$ \\
S9 & Wood and products of wood & $\mathrm{s} 9$ \\
S10 & Paper and products for culture, education and sports & $\mathrm{s} 10$ \\
S11 & Chemined and chemical products & $\mathrm{s} 11$ \\
S12 & Nonmetallic mineral products & $\mathrm{s} 12$ \\
S13 & Metal smelting and rolling processing & $\mathrm{s} 13$ \\
S14 & Manufacture of fabricated metal products & $\mathrm{s} 14$ \\
S15 & Common and special equipment & $\mathrm{s} 15$ \\
S16 & Transport equipment & $\mathrm{s} 16$ \\
S17 & Electrical machinery and apparatus & $\mathrm{s} 17$ \\
S18 & Croducts, coking products and nuclear fuel products & $\mathrm{s} 18$ \\
S19 & Communications, computer and other electronic equipment and apparatuses & $\mathrm{s} 19$ \\
S20 & Instruments, meters, cultural and office machinery & $\mathrm{s} 20$ \\
S21 & Other industrial activities & $\mathrm{s} 21-\mathrm{s} 22$ \\
S22 & Production and distribution of electricity and heat & $\mathrm{s} 23$ \\
S23 & Steam supply & $\mathrm{s} 24$ \\
S24 & Water supply & $\mathrm{s} 25$ \\
S25 & Construction & $\mathrm{s} 26$ \\
S26 & Other service activities & $\mathrm{s} 30-\mathrm{s} 31$ \\
S27 & s27-s28 \\
S28 & Wholesale, retail, accommodation, eating and drinking services & $\mathrm{s} 32-\mathrm{s} 42$ \\
\hline
\end{tabular}

\section{Tangshan's Industrial Structure and Energy Consumption Status}

\subsection{Tangshan's Economic Status}

The city of Tangshan, which is located in the eastern part of Hebei Province, is one of China's most important sites of iron and steel production (Figure 1). For example, in 2012, the crude steel production of this region was 81.07 million tons, $11.3 \%$ of total Chinese production, and $5.2 \%$ of world production. Steel production in this city has grown $9.64 \%$ annually since 2007, while the total GDP of Tangshan in 2012 was 586.16 billion Yuan, 1.1\% of total Chinese GDP. The annual increase in the GDP of Tangshan is $13.01 \%, 0.75 \%$ higher than the national average. Available data shows that this city has a high GDP growth rate, alongside large-scale heavy industrial activity.

Data shows that the proportion of secondary industry within the city of Tangshan rose from $57.4 \%$ in 2007 to $59.3 \%$ in 2012 (Figure 2), while over the same period, this proportion within Hebei Province and across China generally slightly decreased (from $53.3 \%$ to $52.7 \%$ and from $47.3 \%$ to $45.3 \%$, respectively). This trend shows that the economy of the city of Tangshan is highly reliant on secondary industry.

Energy consumption in Tangshan is still growing rapidly. Energy consumption nearly doubled from 60.3 Mtce in 2005 to 113.1 Mtce in 2013, with an average annual increase of $8.2 \%$ (Figure 3). Over this time period, however, the factors contributing to energy consumption have remained constant, although the proportion that can be attributed to coal and coke-coal decreased very slightly from $96.2 \%$ of the total in 2007 to $95.1 \%$ of the total in 2012 . 

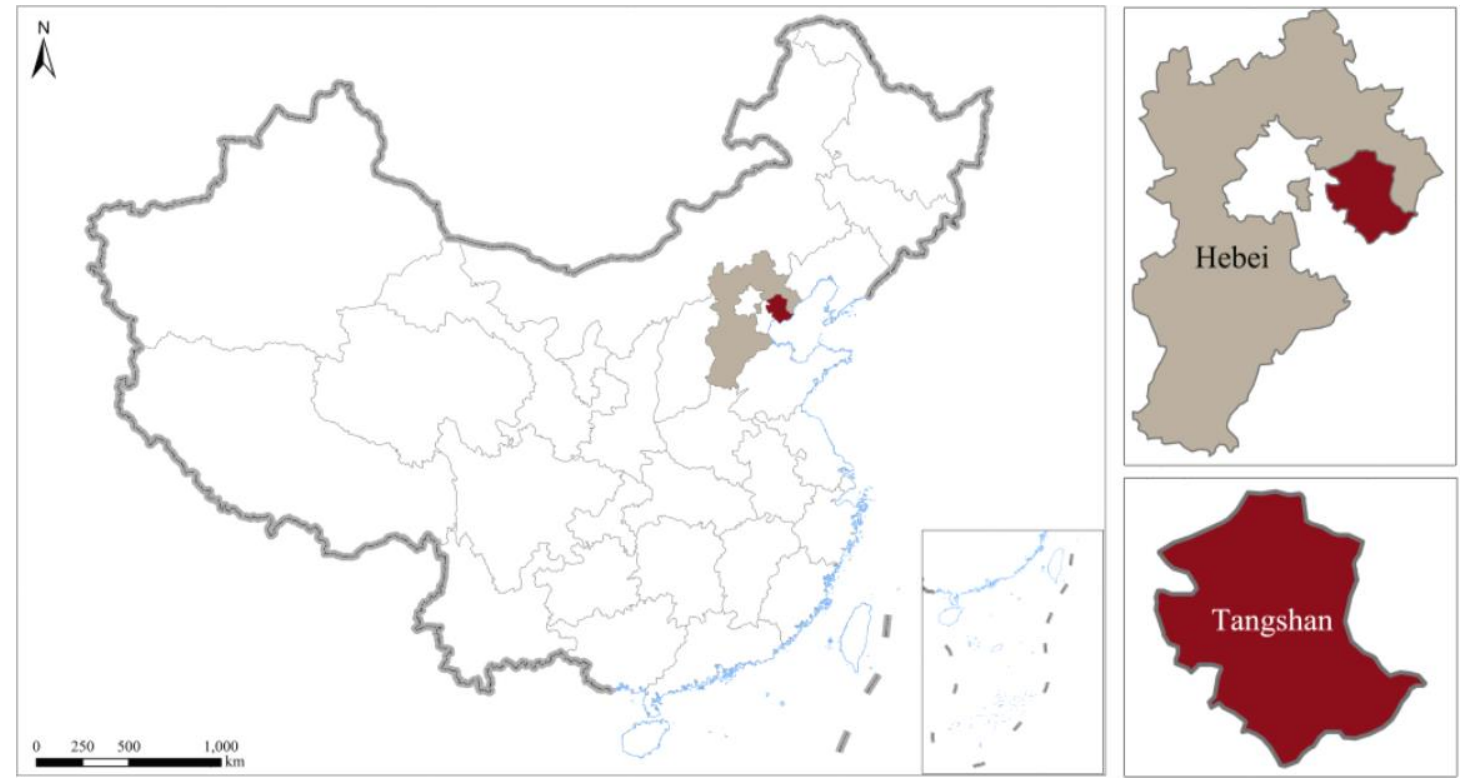

Figure 1. Location of the city of Tangshan.

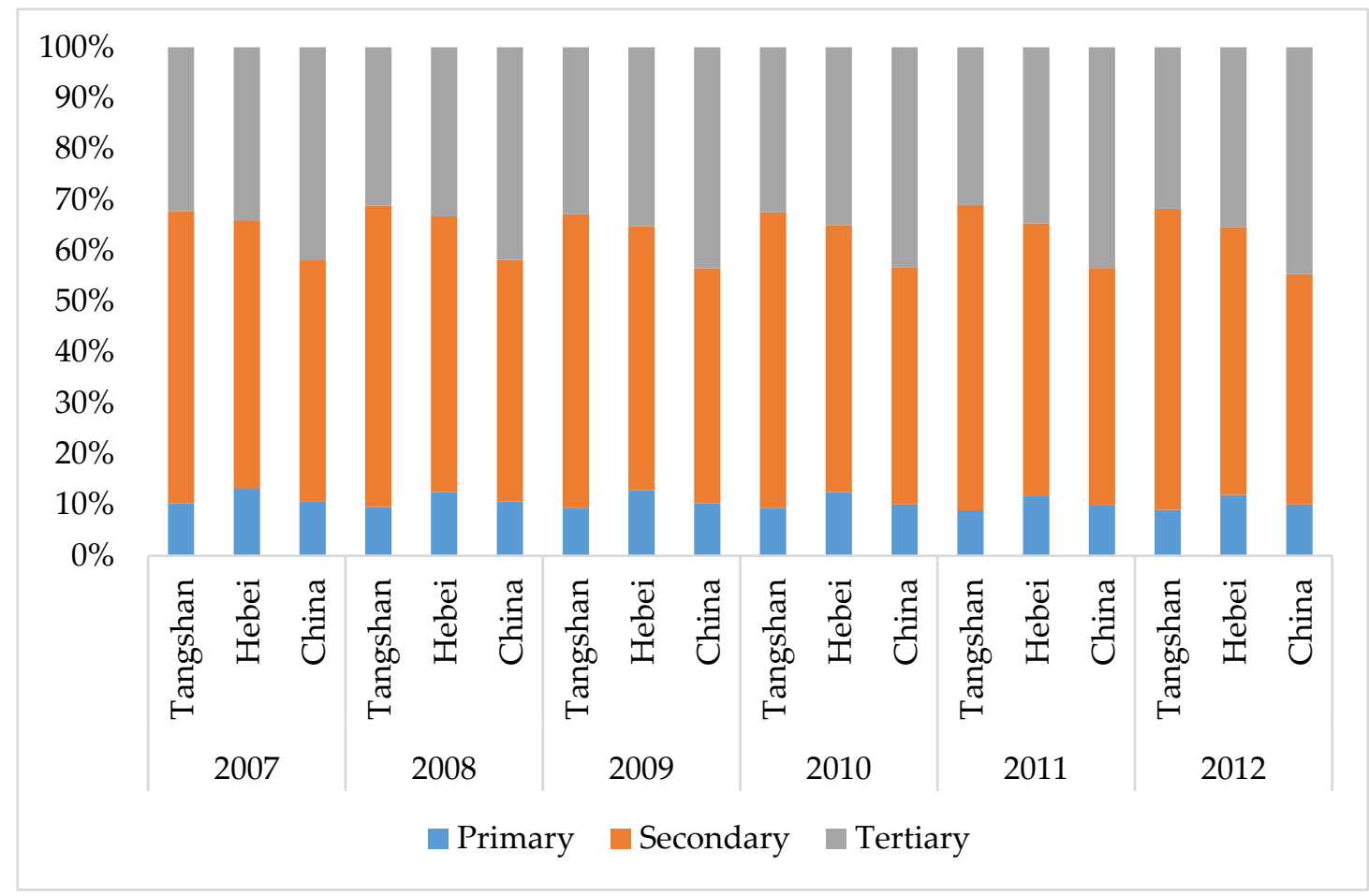

Figure 2. Industrial proportions in the city of Tangshan, in Hebei Province, and across China, between 2007 and 2012. 


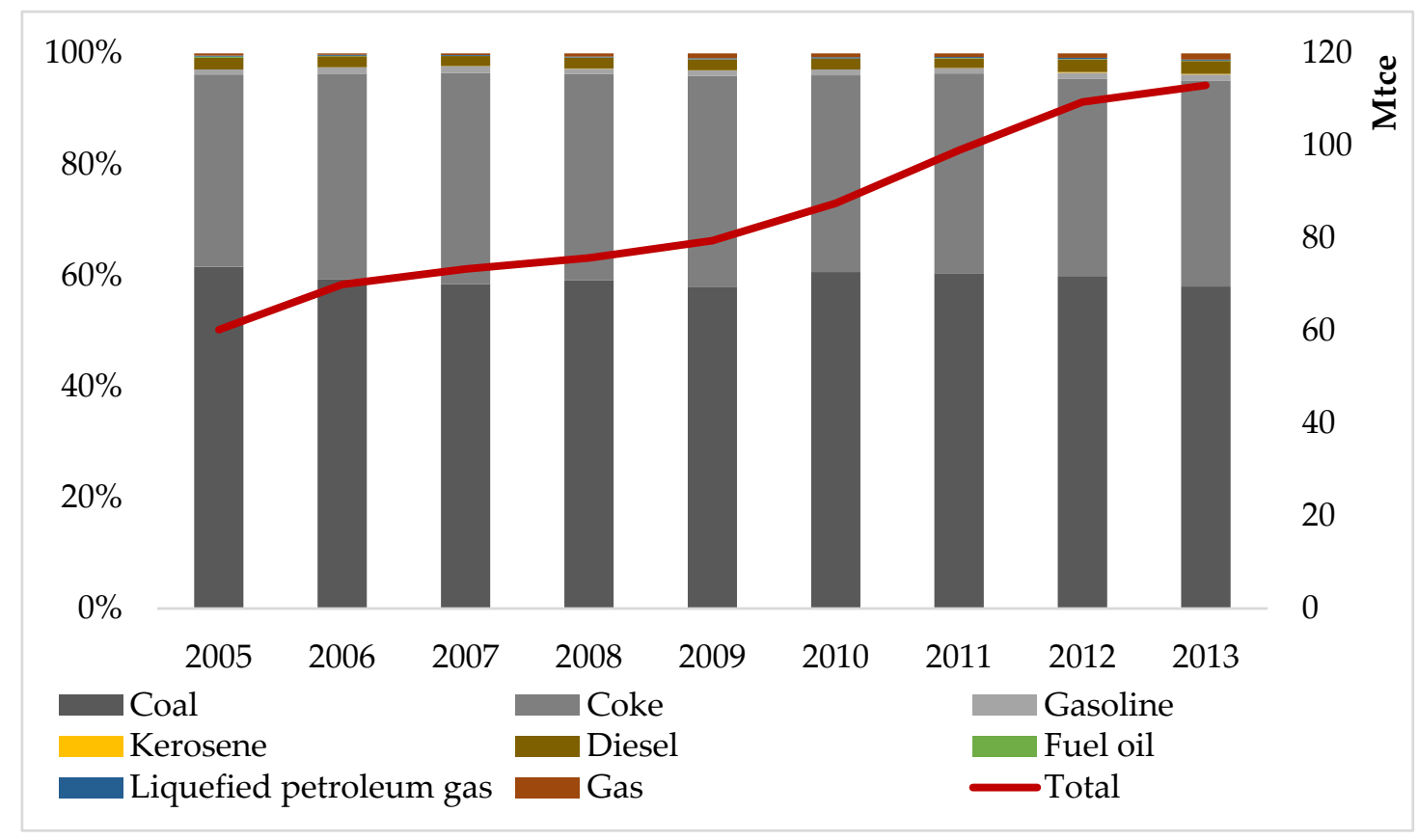

Figure 3. The structure of energy consumption in the city of Tangshan between 2005 and 2013.

\subsection{Trend of Tangshan's Energy Consumption}

Data also show that the energy intensity of Tangshan is higher than the average for Hebei Province, and much higher than the national average (Figure 4). In 2005, for example, the energy intensity of the city of Tangshan was 3.00 tce per 10 thousand Yuan, 1.5 times the average for Hebei Province, and more than twice the national average. Similarly, in 2013, the energy intensity of this city was 1.85 tce per 10 thousand Yuan, translating to an average annual decrease of 5.9\% since 2005. At the same time, the average in 2013 for the whole of China was 0.64 tce per 10 thousand Yuan, which translates to an average annual decrease of $9.3 \%$, much higher than that of the city of Tangshan. The average energy intensity for this city was three times the national average in 2013; the reasons underlying this are likely slow adjustments in the industrial structure of this region as well as the high proportion of heavy industry.

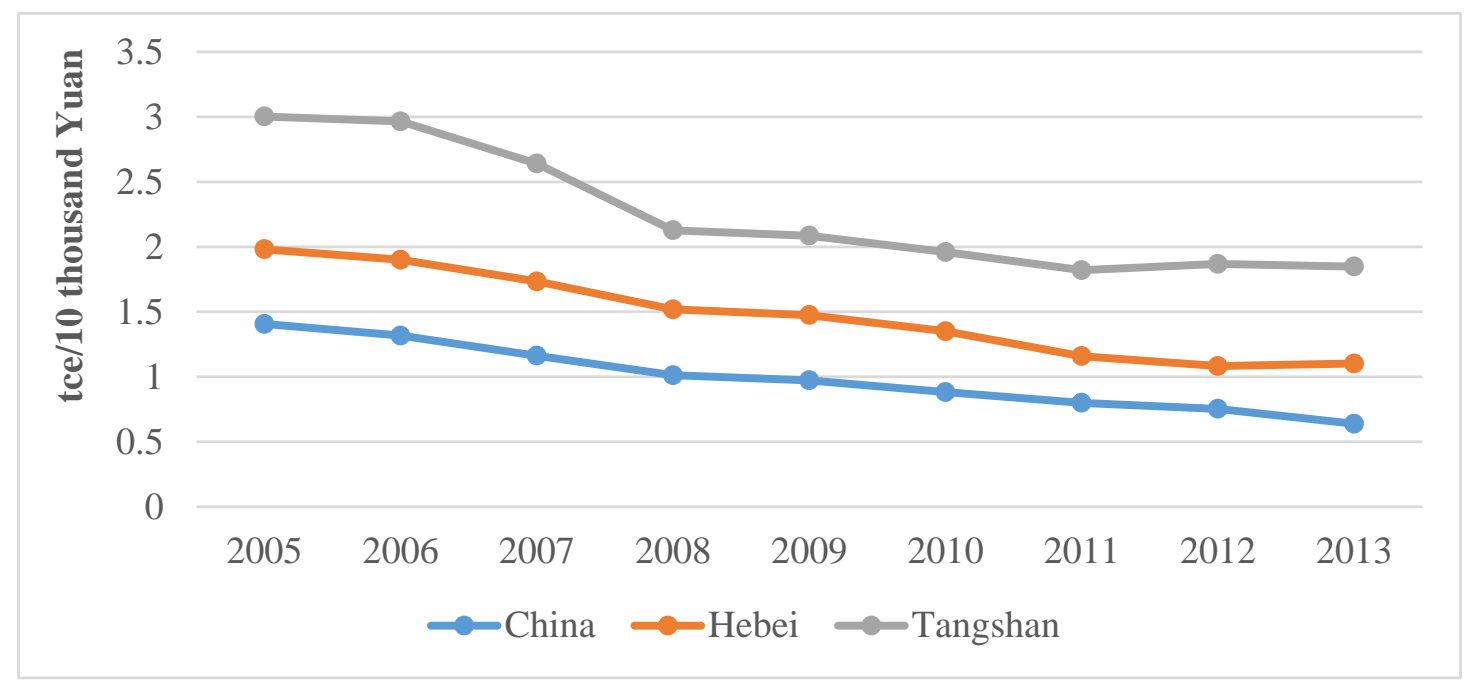

Figure 4. Energy intensity values for China, Hebei Province, and the city of Tangshan between 2005 and 2013. 


\section{Results}

Decomposition results for energy consumption in the city of Tangshan between 2007 and 2012 are listed in Tables 2 and 3.

Total energy consumption increased from 2007 to 2012 in most sectors, except for water production and supply (S24), coal mining and allied production (S2), food and tobacco (S6), oil and gas products (S3), paper printing and stationery (S10), and electricity and heat production and supply (S22). Among the sectors, electricity and heat production and supply (S22) had the largest reduction in energy consumption ( 237,211 tce), followed by paper printing and stationery (S10), oil and gas mining (S3), and tobacco, food, and beverage industries (S6), as well as the coal mining and allied products industry (S2). The energy consumption in all other sectors increased from 2007 to 2012. The metal productions fabrication industry (S15) had the largest increase (3,087,521 tce), followed by construction (S25), metal smelting and rolling processing (S14), chemicals (S12), and special equipment manufacturing.

Table 2. Four factors affecting change in energy consumption in Tangshan between 2007 and 2012 (unit: tce).

\begin{tabular}{|c|c|c|c|c|c|}
\hline Sectors & $\begin{array}{c}\text { Technical } \\
\text { Effect }\left(\Delta e^{T}\right)\end{array}$ & $\begin{array}{l}\text { Input Structural } \\
\text { Effect }(\Delta C)\end{array}$ & $\begin{array}{c}\text { Final Use Structural } \\
\text { Effect }(\Delta s)\end{array}$ & $\begin{array}{c}\text { Final Use Scale } \\
\text { Effect }(\Delta y)\end{array}$ & Total \\
\hline S1 & $-74,695$ & 80,126 & 194,642 & 224,677 & 424,751 \\
\hline $\mathrm{S} 2$ & 22,930 & 105,832 & $-250,824$ & 99,112 & $-22,950$ \\
\hline S3 & -4291 & 51,590 & $-178,243$ & 37,542 & $-93,401$ \\
\hline S4 & $-79,659$ & $-231,741$ & 508,055 & 157,414 & 354,069 \\
\hline S5 & -478 & -110 & 4237 & 1145 & 4793 \\
\hline S6 & $-44,996$ & 28,481 & $-162,919$ & 116,485 & $-62,950$ \\
\hline S7 & -1807 & 5558 & 10,701 & 6634 & 21,086 \\
\hline S8 & 1713 & 21,841 & 13,723 & 39,790 & 77,068 \\
\hline S9 & -3731 & 11,453 & 219 & 16,443 & 24,384 \\
\hline S10 & $-147,921$ & 95,287 & $-177,974$ & 80,801 & $-149,806$ \\
\hline S11 & $-54,143$ & 58,660 & 159,947 & 85,983 & 250,448 \\
\hline S12 & $-100,684$ & 299,364 & 408,627 & 359,777 & 967,084 \\
\hline S13 & $-343,478$ & 159,661 & $-266,913$ & 473,057 & 22,326 \\
\hline S14 & $-1,529,899$ & $1,354,136$ & $-3,061,704$ & $4,525,199$ & $1,287,732$ \\
\hline S15 & $-175,296$ & 247,119 & $2,613,564$ & 402,134 & $3,087,521$ \\
\hline S16 & $-140,587$ & 211,169 & 232,051 & 460,788 & 763,420 \\
\hline S17 & $-55,375$ & 108,125 & 322,080 & 154,334 & 529,163 \\
\hline S18 & $-23,209$ & 30,469 & 256,474 & 59,569 & 323,304 \\
\hline S19 & $-13,573$ & -7851 & 40,821 & 29,707 & 49,104 \\
\hline S20 & -2102 & 1117 & 370 & 5704 & 5089 \\
\hline $\mathrm{S} 21$ & -1690 & 68,930 & 62,814 & 8909 & 138,963 \\
\hline $\mathrm{S} 22$ & $-260,443$ & 236,167 & $-621,405$ & 408,409 & $-237,271$ \\
\hline $\mathrm{S} 23$ & -1074 & 5450 & -2290 & 4526 & 6612 \\
\hline $\mathrm{S} 24$ & -3185 & -4035 & -2163 & 2824 & -6558 \\
\hline $\mathrm{S} 25$ & $-322,179$ & $1,219,034$ & $-359,083$ & 805,683 & $1,343,455$ \\
\hline $\mathrm{S} 26$ & 150,133 & 12,110 & $-144,366$ & 184,400 & 202,277 \\
\hline $\mathrm{S} 27$ & $-176,588$ & 103,436 & $-125,096$ & 295,452 & 97,204 \\
\hline S28 & 243,599 & 75,314 & $-522,242$ & 348,595 & 145,266 \\
\hline
\end{tabular}

In terms of reducing energy consumption, technical changes proved to be the most important factor. The three sectors with the largest reduction in energy consumption attributable to technical change were metal smelting (1,529,898 tce), non-metallic minerals (343,478 tce), and construction (322,179 tce). Input structural effects led to increases in energy consumption in most sectors. Metal smelting and rolling processing (S14), construction (S25), and chemicals (S12) were the three sectors with the largest increase in energy consumption caused by structural change, mainly because of increased production in these industries. The demand for intermediate inputs also increased, resulting in increased demand for intermediate energy consumption. Finally, final use scale effects also increased 
energy consumption in all sectors; the largest such increases were seen in the metal smelting and construction industries (S14) as this sector experienced the greatest production growth.

Table 3. Four factors contributing to the change in energy consumption in Tangshan from 2007 to 2012.

\begin{tabular}{|c|c|c|c|c|c|c|}
\hline Sectors & $\begin{array}{c}\text { Technical } \\
\text { Effect }\left(\Delta e^{T}\right)\end{array}$ & $\begin{array}{c}\text { Input Structural } \\
\text { Effect }(\Delta C)\end{array}$ & $\begin{array}{c}\text { Final Use Structural } \\
\text { Effect }(\Delta s)\end{array}$ & $\begin{array}{l}\text { Final Use Scale } \\
\text { Effect }(\Delta y)\end{array}$ & $\begin{array}{l}\text { Total Energy } \\
\text { Consumption } \\
\text { Change }\end{array}$ & $\begin{array}{l}\text { Total Energy } \\
\text { Consumption } \\
\text { in } 2007 \text { (tce) }\end{array}$ \\
\hline S1 & $-16.8 \%$ & $18.0 \%$ & $43.7 \%$ & $50.5 \%$ & $95.4 \%$ & $445,119.9$ \\
\hline $\mathrm{S} 2$ & $7.9 \%$ & $36.3 \%$ & $-86.1 \%$ & $34.0 \%$ & $-7.9 \%$ & $291,288.5$ \\
\hline S3 & $-2.7 \%$ & $32.4 \%$ & $-111.8 \%$ & $23.6 \%$ & $-58.6 \%$ & $159,406.6$ \\
\hline $\mathrm{S} 4$ & $-27.4 \%$ & $-79.8 \%$ & $174.9 \%$ & $54.2 \%$ & $121.9 \%$ & $290,405.4$ \\
\hline S5 & $-34.0 \%$ & $-7.8 \%$ & $301.5 \%$ & $81.4 \%$ & $341.0 \%$ & 1405.5 \\
\hline S6 & $-12.5 \%$ & $7.9 \%$ & $-45.1 \%$ & $32.3 \%$ & $-17.4 \%$ & $361,155.4$ \\
\hline S7 & $-17.9 \%$ & $55.0 \%$ & $105.8 \%$ & $65.6 \%$ & $208.5 \%$ & $10,114.3$ \\
\hline S8 & $2.2 \%$ & $28.0 \%$ & $17.6 \%$ & $50.9 \%$ & $98.7 \%$ & $78,113.5$ \\
\hline S9 & $-10.6 \%$ & $32.5 \%$ & $0.6 \%$ & $46.6 \%$ & $69.1 \%$ & $35,266.1$ \\
\hline S10 & $-47.6 \%$ & $30.6 \%$ & $-57.2 \%$ & $26.0 \%$ & $-48.2 \%$ & $311,037.4$ \\
\hline S11 & $-39.1 \%$ & $42.3 \%$ & $115.4 \%$ & $62.1 \%$ & $180.7 \%$ & $138,560.3$ \\
\hline S12 & $-16.6 \%$ & $49.3 \%$ & $67.3 \%$ & $59.2 \%$ & $159.3 \%$ & $607,252.0$ \\
\hline $\mathrm{S} 13$ & $-25.9 \%$ & $12.1 \%$ & $-20.2 \%$ & $35.7 \%$ & $1.7 \%$ & $1,323,656.8$ \\
\hline S14 & $-12.6 \%$ & $11.2 \%$ & $-25.2 \%$ & $37.3 \%$ & $10.6 \%$ & $12,135,370.7$ \\
\hline S15 & $-80.6 \%$ & $113.6 \%$ & $1201.7 \%$ & $184.9 \%$ & $1419.7 \%$ & $217,484.2$ \\
\hline S16 & $-14.7 \%$ & $22.1 \%$ & $24.3 \%$ & $48.2 \%$ & $79.9 \%$ & $955,602.3$ \\
\hline S17 & $-24.8 \%$ & $48.4 \%$ & $144.3 \%$ & $69.1 \%$ & $237.1 \%$ & $223,200.8$ \\
\hline S18 & $-42.0 \%$ & $55.1 \%$ & $463.7 \%$ & $107.7 \%$ & $584.5 \%$ & $55,314.3$ \\
\hline S19 & $-22.0 \%$ & $-12.7 \%$ & $66.2 \%$ & $48.2 \%$ & $79.6 \%$ & $61,653.7$ \\
\hline S20 & $-15.4 \%$ & $8.2 \%$ & $2.7 \%$ & $41.7 \%$ & $37.2 \%$ & $13,683.1$ \\
\hline S21 & $-304.9 \%$ & $12,434.1 \%$ & $11,330.9 \%$ & $1607.0 \%$ & $25,067.1 \%$ & 554.4 \\
\hline $\mathrm{S} 22$ & $-20.4 \%$ & $18.5 \%$ & $-48.7 \%$ & $32.0 \%$ & $-18.6 \%$ & $1,275,082.0$ \\
\hline S23 & $-11.0 \%$ & $55.9 \%$ & $-23.5 \%$ & $46.4 \%$ & $67.8 \%$ & 9748.1 \\
\hline $\mathrm{S} 24$ & $-27.2 \%$ & $-34.5 \%$ & $-18.5 \%$ & $24.2 \%$ & $-56.1 \%$ & $11,693.3$ \\
\hline $\mathrm{S} 25$ & $-19.3 \%$ & $73.1 \%$ & $-21.5 \%$ & $48.3 \%$ & $80.6 \%$ & $1,667,386.0$ \\
\hline S26 & $35.3 \%$ & $2.8 \%$ & $-33.9 \%$ & $43.3 \%$ & $47.5 \%$ & $425,704.5$ \\
\hline S27 & $-22.5 \%$ & $13.2 \%$ & $-15.9 \%$ & $37.6 \%$ & $12.4 \%$ & $785,997.8$ \\
\hline S28 & $26.7 \%$ & $8.3 \%$ & $-57.2 \%$ & $38.2 \%$ & $15.9 \%$ & $912,758.7$ \\
\hline
\end{tabular}

Data show that in terms of sectors that experienced an increase in energy consumption between 2007 and 2012, transport equipment (S17) exhibited the largest increase, by more than $200 \%$, compared to other industrial activities (S21), manufacture of fabricated metal products (S15), electrical machinery and apparatus (S18), and the mining of nonmetal (S5). In terms of how each factor affected changes in energy consumption relative to 2007, data also show that 24 of the 28 experienced negative technical changes, which means that the majority made technical improvements to reduce energy consumption. Other industrial activities (S21), manufacture of fabricated metal products (S15), paper and products for culture, education and sports (S10) had the greatest technical effect. As for input structural effect, 24 of 28 sectors had positive effect in increasing energy consumption, manufacture of fabricated metal products (S15), construction (S25), steam supply (S23), electrical machinery and apparatus (S18), and textile (S7), which all had an over 50\% energy consumption increase. In term of final use structural effect, about half of the sectors had a positive effect in increasing energy consumption. The other industrial activities (S21), manufacture of fabricated metal products (S15), electrical machinery and apparatus (S18), mining of nonmetal (S5), and mining of metal (S4) had the most obvious final use structural effect in increasing energy consumption, while mining of oil and gas (S3), mining of coal (S2), paper and products for culture, education, and sports (S10), and other service activities (S28) had the most significant final use scale effect in decreasing energy consumption. All sectors had a positive final use scale effect in increasing energy consumption. Sectors like other industrial activities (S21), manufacture of fabricated metal products (S15), and electrical machinery and apparatus (S18) had an $100 \%$ increase in energy consumption, which was affected by final use scale effect.

A number of key sectors contribute to a larger proportion of energy consumption in the city of Tangshan, including metal smelting and rolling processing (S14) which accounted for $53.2 \%$ of energy consumption in 2007, and increased 10.6\% between 2007 and 2012. Results show that the four factors 
tested here contributed to $-12.6 \%$ (technical effects), $11.2 \%$ (input structural effects), $-25.2 \%$ (final use structural effects), and 37.3\% (final use scale effect) increases in consumption between 2007 and 2012.

\section{Conclusions and Policy Implications}

In order to identify the factors contributing to changes in energy consumption in the city of Tangshan, we first analyzed current economic development and industrial structure within this region and then considered energy consumption. We used previously developed methods to determine the nature of factors affecting changes in energy consumption within the city of Tangshan. The four main conclusions of this research are summarized below.

(1) From 2007 to 2012, the growth in GDP in the city of Tangshan was higher than the national average. Secondary industry output in Tangshan city accounts for an extremely high proportion of total GDP, much higher than the national average. This proportion translates into a rising trend, instead of a declining trend, in energy consumption during the studied period.

(2) As a result of Tangshan's economic development, Tangshan's energy consumption in 2013 was nearly twice that in 2005. Coal and coke coal consumption was responsible for $96.2 \%$ of total energy consumption in 2005 and $95.1 \%$ in 2013, demonstrating that coal-related energy is the primary energy source, and that the energy consumption structure did not change significantly between 2005 and 2013.

(3) In light of the increasing GDP and energy consumption, energy intensity has been gradually decreasing in Tangshan city. Tangshan's energy intensity decreased from 3.00 tce/10 thousand Yuan in 2005 to 1.85 tce/10 thousand Yuan in 2013. However, the energy intensity of Tangshan was far greater than the average in China, and the rate of decrease in Tangshan's energy intensity was much lower than China's average.

(4) In Tangshan city, the industries with the largest increases in energy consumption from 2007 to 2012 were metal products, construction, and metal smelting and rolling processing. Among the factors contributing to changes in energy consumption, the technical effect was the most important in decreasing energy consumption in most sectors, while the scale effect was the most important contributor to increases in energy consumption in all sectors. In contrast, the input structural and final use structural effects played different roles in different sectors.

In terms of policy, one obvious dilemma associated with reducing the energy consumption of the city of Tangshan is the dominance of heavy industry. Because the mining of metals, fabrication of metal products, and construction contribute the most overall to increasing energy consumption, any reduction brought about by technical changes to these industries will hardly offset corresponding increases caused by intermediate structural inputs and end-user consumption effects. Thus, strategies to significantly reduce energy consumption in the short term include adjustments to industrial structures and the development of low-energy-intensity industries. It is clear that strategies need to be implemented in policy in order to practically engage in the rationalization of industrial structures and modes-of-production. Improvements are required to both administrative and economic policies.

Our analysis of the effects of scale and technical factors show that, in terms of administrative policies, improving and enhancing the control of energy consumption standards as well as transforming the mode of economic growth to technique-oriented should be clear priorities if industrial production in the city of Tangshan is to be successfully adjusted. To do this, the government needs to strictly control the emissions of newly-added industrial producers in order to curb continued expansion of high energy consumption and high emissions, while at the same time, in terms of dealing with existing high energy consumption industries, we suggest that several typical enterprises are selected that exhibit the most energy saving potential so that available administrative resources are most effectively utilized in cutting energy consumption and in setting industry standards. It is also necessary that the government makes significant efforts to improve industrial production and techniques for the treatment of pollutants through investment and by encouraging research and development. Technical 
departments across all sectors would then be encouraged to try to solve these problems at their source. In addition, techniques involving administrative innovation also play equally important roles in steering reductions in energy consumption.

It is not sufficient or appropriate to simply rely on administrative means to reduce energy consumption as the market presently plays a much enhanced role. Thus, coordinating with administrative powers, the government of the city of Tangshan must adjust the local fiscal and taxation system and implement a number of other financial measures to directly lead and shape the development of industries. For example, the city government could levy high taxation on products from very heavily polluting and high energy consuming industries, while at the same time lowering taxation on enterprises that implement energy-conserving and emission-reducing production measures. In addition, the government could also waive administrative examination and approval fees for companies that replace traditional energy sources with renewable ones. The use of a range of different kinds of economic stimuli can move entire industries in the direction of energy conservation.

Acknowledgments: This paper is supported by the key research and development plan (grant No. 2016YFA0602804) and the National Natural Science Foundation of China (grants No. 41430636; No. 41571518; No. 41201129).

Author Contributions: Jialing Zou, Zhipeng Tang, and Weidong Liu conceived and designed the experiments; Zhipeng Tang performed the experiments; Jialing Zou and Zhipeng Tang analyzed the data; Zhipeng Tang contributed analysis tools; Jialing Zou and Zhipeng Tang wrote the paper.

Conflicts of Interest: The authors declare no conflict of interest.

\section{Appendix}

Table A1. Sectors of input-output table.

\begin{tabular}{cc}
\hline $\begin{array}{c}\text { Original Sectors of } \\
\text { Input-Output Table }\end{array}$ & Description \\
\hline s1 & Agriculture \\
s2 & Mining of coal \\
s3 & Mining of oil and gas \\
s4 & Mining of metal \\
s5 & Mining of nonmetal \\
s6 & Tobacco, food and beverage \\
s7 & Textile \\
s8 & Wearing apparel, dressing and dyeing of fur \\
s9 & Wood and products of wood \\
s10 & Paper and products for culture, education and sports \\
s11 & Chemicals and chemical products \\
s12 & Nonmetallic mineral products \\
s14 & Mefined petroleum products, coking products and nuclear fuel products \\
s15 & Metal smelting and rolling processing \\
s16 & Manufacture of fabricated metal products \\
s17 & Common and special equipment \\
s18 & Transport equipment \\
s19 & Electrical machinery and apparatus \\
s20 & Communications, computer and other electronic equipment and apparatuses \\
s21 & Instruments, meters, cultural and office machinery \\
s22 & Other manufacturing products \\
s23 & Scrap and waste \\
s24 & s25 \\
s26 & Production and distribution of electricity and heat \\
& Steam supply \\
\hline & Water supply \\
\hline
\end{tabular}


Table A1. Cont.

\begin{tabular}{cc}
\hline $\begin{array}{c}\text { Original Sectors of } \\
\text { Input-Output Table }\end{array}$ & Description \\
\hline s27 & Transport and warehousing \\
s28 & Post \\
s29 & Information communication, computer service and software \\
s30 & Wholesale and retail trade \\
s31 & Accommodation, eating and drinking places \\
s32 & Finance and insurance \\
s33 & Real estate \\
s34 & Renting and commercial service \\
s35 & Tourism \\
s36 37 & Scientific research \\
38 & General technical services \\
39 & Other social services \\
s40 & Education \\
s41 & Culture, sports and amusements \\
s42 & Health service, social guarantee and social welfare \\
& Public management and social administration \\
\hline
\end{tabular}

\section{References}

1. State Council of China. "12th Five-Year Plan" Program of Work to Control Greenhouse Gas Emissions. Available online: http://www.gov.cn/zwgk/2012-01/13/content_2043645.htm (accessed on 18 December 2016). (In Chinese)

2. State Council of China. "13th Five-Year Plan" Program of Work to Control Greenhouse Gas Emissions. Available online: http://www.gov.cn/zhengce/content/2016-11/04/content_5128619.htm (accessed on 18 December 2016). (In Chinese)

3. Li, W.; Yang, M.; Shi, P. Analysis for the relationship between Tangshan industrial structure and its environmental impacts. Geogr. Res. 2002, 4, 13. (In Chinese)

4. Yang, Y.H.; Dai, D.F. Analysis of Energy Consumption and Carbon Emission in Tangshan City. CO-Oerativeconomy Sci. 2016, 8, 46-47. (In Chinese)

5. Han, R.; Zhang, Q.; Zhu, S.; Chen, Y. Industrial Economy and Energy TFP of Tangshan City based on DEA and Malmquist Model. Sci. Geogr. Sin. Available online: http://www.cnki.net/kcms/detail/22.1124.P. 20161123.1113.008.html (accessed on 6 January 2017). (In Chinese)

6. $\mathrm{Xu}, \mathrm{X} . \mathrm{Y}$; Ang, B.W. Index decomposition analysis applied to $\mathrm{CO}_{2}$ emission studies. Ecol. Econ. 2013, 93, 313-329. [CrossRef]

7. Su, B.; Ang, B.W. Structural decomposition analysis applied to energy and emissions: Some methodological developments. Energy Econ. 2012, 34, 177-188. [CrossRef]

8. Su, B.; Ang, B.W. Multiplicative decomposition of aggregate carbon intensity change using input-output analysis. Appl. Energy 2015, 154, 13-20. [CrossRef]

9. $\mathrm{Su}, \mathrm{B}$; Ang, B.W. Attribution of changes in the generalized Fisher index with application to embodied emission studies. Energy 2014, 69, 778-786. [CrossRef]

10. Su, B.; Ang, B.W. Multi-region comparisons of emission performance: The structural decomposition analysis approach. Ecol. Indic. 2016, 67, 78-87. [CrossRef]

11. Wachsmann, U.; Wood, R.; Lenzen, M.; Schaeffer, R. Structural decomposition of energy use in Brazil from 1970 to 1996. Appl. Energy 2009, 86, 578-587. [CrossRef]

12. Weber, C.L. Measuring structural change and energy use: Decomposition of the US economy from 1997 to 2002. Energy Policy 2009, 37, 1561-1570. [CrossRef]

13. Kim, J.; Heo, E. Sources of structural change in energy use: A decomposition analysis for Korea. Energy Source Part B 2016, 11, 309-313. [CrossRef]

14. Cellura, M.; Longo, S.; Mistretta, M. Application of the Structural Decomposition Analysis to assess the indirect energy consumption and air emission changes related to Italian households consumption. Renew. Sustain. Energy Rev. 2012, 16, 1135-1145. [CrossRef] 
15. Department of Energy Statistics, National Bureau of Statistics. China Energy Statistical Yearbook 2015; China Statistical Press: Beijing, China, 2015. (In Chinese)

16. Xia, Y.; Yang, C.; Chen, X. Analysis on determining factors of energy intensity in China based on comparable price input-output table. Syst. Eng. Theory Pract. 2009, 10, 4. (In Chinese)

17. Li, F.; Song, Z.; Liu, W. China's energy consumption under the global economic crisis: Decomposition and sectoral analysis. Energy Policy 2014, 64, 193-202. [CrossRef]

18. Zhang, H.; Lahr, M.L. China's energy consumption change from 1987 to 2007: A multi-regional structural decomposition analysis. Energy Policy 2014, 67, 682-693. [CrossRef]

19. Zeng, L.; Xu, M.; Liang, S.; Zeng, S.; Zhang, T. Revisiting drivers of energy intensity in China during 1997-2007: A structural decomposition analysis. Energy Policy 2014, 67, 640-647. [CrossRef]

20. Zhao, X.; Ma, C.; Hong, D. Why did China's energy intensity increase during 1998-2006: Decomposition and policy analysis? Energy Policy 2010, 38, 1379-1388. [CrossRef]

21. Lin, X.; Polenske, K.R. Input-output anatomy of China's energy use changes in the 1980s. Econ. Syst. Res. 1995, 7, 67-84. [CrossRef]

22. Song, P.; Ji, J.; Ma, X. Structural decomposition analysis on the growth of carbon emission from energy consumption in Guangdong. Resour. Sci. 2012, 34, 551-558. (In Chinese)

23. Ang, B.W.; Zhang, F.Q.; Choi, K. Factorizing changes in energy and environmental indicators through decomposition. Energy 1998, 23, 489-495. [CrossRef]

24. Ang, B.W.; Liu, F.L.; Chew, E.P. Perfect decomposition techniques in energy and environmental analysis. Energy Policy 2003, 31, 1561-1566. [CrossRef]

25. Ang, B.W. Decomposition analysis for policymaking in energy: which is the preferred method? Energy Policy 2004, 32, 1131-1139. [CrossRef]

26. Li, G.; Wang, S. Regional Factor Decompositions in China's Energy Intensity Change: Base on LMDI Technique. J. Financ. Econ. 2008, 34, 52-62. (In Chinese)

27. Zhang, M.; Mu, H.; Ning, Y.; Song, Y. Decomposition of energy-related $\mathrm{CO}_{2}$ emission over 1991-2006 in China. Ecol. Econ. 2009, 68, 2122-2128. [CrossRef]

28. Wang, W.W.; Zhang, M.; Zhou, M. Using LMDI method to analyze transport sector $\mathrm{CO}_{2}$ emissions in China. Energy 2011, 36, 5909-5915. [CrossRef]

29. Nie, H.; Kemp, R. Index decomposition analysis of residential energy consumption in China: 2002-2010. Appl. Energy 2014, 121, 10-19. [CrossRef]

30. Fernández González, P.; Landajo, M.; Presno, M.J. Multilevel LMDI decomposition of changes in aggregate energy consumption. A cross country analysis in the EU-27. Energy Policy 2014, 68, 576-584. [CrossRef]

31. Zhang, Y.; Tang, Z.P. Driving factors of carbon embodied in China's provincial exports. Energy Econ. 2015, 51, 445-454. [CrossRef]

32. Zhao, M.; Tan, L.; Zhang, W.; Ji, M.; Liu, Y.; Yu, L. Decomposing the influencing factors of industrial carbon emissions in Shanghai using the LMDI method. Energy 2010, 35, 2505-2510. [CrossRef]

33. Yang, J.; Chen, B. Using LMDI method to analyze the change of industrial $\mathrm{CO}_{2}$ emission from energy use in Chongqing. Front. Earth Sci. 2011, 5, 103-109. [CrossRef]

34. Jiekun, S. Factor Decomposition of Carbon Emissions from Energy Consumption of Shandong Province Based on LMDI. Resour. Sci. 2012, 1, 8. (In Chinese)

35. Zhang, J.; Zhang, Y.; Yang, Z.; Fath, B.D.; Li, S. Estimation of energy-related carbon emissions in Beijing and factor decomposition analysis. Ecol. Model. 2013, 252, 258-265. [CrossRef]

36. Wang, Z.; Zhao, L.; Mao, G.; Wu, B. Factor Decomposition Analysis of Energy-Related $\mathrm{CO}_{2}$ Emissions in Tianjin, China. Sustainability 2015, 7, 9973-9988. [CrossRef]

37. Zhang, W.; Li, K.; Zhou, D.; Zhang, W.; Gao, H. Decomposition of intensity of energy-related $\mathrm{CO}_{2}$ emission in Chinese provinces using the LMDI method. Energy Policy 2016, 92, 369-381. [CrossRef]

38. Vause, J.; Gao, L.; Shi, L.; Zhao, J. Production and consumption accounting of $\mathrm{CO}_{2}$ emissions for Xiamen, China. Energy Policy 2013, 60, 697-704. [CrossRef]

39. Choi, K.; Oh, W. Extended Divisia index decomposition of changes in energy intensity: A case of Korean manufacturing industry. Energy Policy 2014, 65, 275-283. [CrossRef]

40. Zhang, M.; Li, H.; Zhou, M.; Mu, H. Decomposition analysis of energy consumption in Chinese transportation sector. Appl. Energy 2011, 88, 2279-2285. [CrossRef] 
41. Wei, Y.; Liao, H.; Fan, Y. An empirical analysis of energy efficiency in China's iron and steel sector. Energy 2007, 32, 2262-2270. [CrossRef]

42. Ying, H.; Ping, M.; Lu, L. A new decomposition method of influential factors on energy consumption intensity. J. Quant. Tech. Econ. 2010, 4, 137-147. (In Chinese)

43. De Boer, P. Additive Structural Decomposition Analysis and Index Number Theory: An Empirical Application of the Montgomery Decomposition. Econ. Syst. Res. 2008, 20, 97-109. [CrossRef]

44. Peng, Y.; Shi, C.; Haiyang, L. The Effect of International Trade on $\mathrm{CO}_{2}$ Emissions Growth in China: Based on a Method Combined SDA with LMDI. Econ. Rev. 2012, 1, 122-132. (In Chinese)

45. Liu, Z.; Geng, Y.; Lindner, S.; Zhao, H.; Fujita, T.; Guan, D. Embodied energy use in China's industrial sectors. Energy Policy 2012, 49, 751-758. [CrossRef]

46. Leontief, W. Environmental repercussions and the economic structure: An input-output approach. Rev. Econ Stat. 1970, 262-271. [CrossRef]

47. Leontief, W.W. Quantitative input and output relations in the economic systems of the United States. Rev. Econ. Stat. 1936, 18, 105-125. [CrossRef]

48. $\mathrm{Su}, \mathrm{B}$; $\mathrm{Ang}, \mathrm{B} . W$. Input-output analysis of $\mathrm{CO}_{2}$ emissions embodied in trade: Competitive versus non-competitive imports. Energy Policy 2013, 56, 83-87. [CrossRef]

49. Ang, B.W. The LMDI approach to decomposition analysis: A practical guide. Energy Policy 2005, 33, 867-871. [CrossRef]

50. Ang, B.W.; Liu, N. Handling zero values in the logarithmic mean Divisia index decomposition approach. Energy Policy 2007, 35, 238-246. [CrossRef]

51. Grossman, G.M.; Krueger, A.B. Environmental Impacts of a North American Free Trade Agreement in the U.S.-Mexico Free Trade Agreement; No. w3914; National Bureau of Economic Research: Cambridge, MA, USA, 1991.

52. Copeland, B.R.; Taylor, M.S. Trade, Growth, and the Environment. J. Econ. Lit. 2004, 42, 7-71. [CrossRef]

53. Hebei Provincial Bureau of Statistics. Tangshan Input-Output Table 2007. 2007. Unpublished work. (In Chinese)

54. Hebei Provincial Bureau of Statistics. Tangshan Input-Output Table 2012. 2012. Unpublished work. (In Chinese)

55. Bureau of Tangshan Statistics. Tangshan Statistical Yearbook; China Statistical Publishing House: Beijing, China, 2008. (In Chinese)

56. Bureau of Tangshan Statistics. Tangshan Statistical Yearbook; China Statistical Publishing House: Beijing, China, 2009. (In Chinese)

57. Bureau of Tangshan Statistics. Tangshan Statistical Yearbook; China Statistical Publishing House: Beijing, China, 2010. (In Chinese)

58. Bureau of Tangshan Statistics. Tangshan Statistical Yearbook; China Statistical Publishing House: Beijing, China, 2011. (In Chinese)

59. Bureau of Tangshan Statistics. Tangshan Statistical Yearbook; China Statistical Publishing House: Beijing, China, 2012. (In Chinese)

60. Bureau of Tangshan Statistics. Tangshan Statistical Yearbook; China Statistical Publishing House: Beijing, China, 2013. (In Chinese)

(C) 2017 by the authors. Licensee MDPI, Basel, Switzerland. This article is an open access article distributed under the terms and conditions of the Creative Commons Attribution (CC BY) license (http:/ / creativecommons.org/licenses/by/4.0/). 